\section{Impact of genetic predisposition of de novo uveitis with etanercept in ankylosing spondylitis}

We read with interest the paper by Sieper $e t a l^{1}$ reporting acute anterior uveitis (AAU) during etanercept or sulfasalazine therapies for axial spondyloarthritis (AxSpA). AAU is a well-known symptom in AxSpA without therapy and is itself a good indication for tumour necrosis factor (TNF) blockers. ${ }^{2}$ However during the last years, new onsets of AAU were reported with TNF blockers, ${ }^{3}$ as a paradoxical effect of this therapy, similarly to paradoxical psoriasis. New onset of AAU occurred mainly in AxSpA (19 cases) compared with other rheumatic conditions (12 cases) according to data from the French nationwide network. ${ }^{4}$

The real mechanism of this type of AAU is not yet elucidated. We would like to suggest a potential genetic predisposition for this type of event by reporting cases in two related patients, both followed for AxSpA in the Department of Rheumatology at University Hospital of Saint-Etienne. They both developed AAU with etanercept therapy, whereas rheumatic symptoms were under control, similarly to many cases reported. ${ }^{4}$ AAU resolved rapidly with local therapy without etanercept discontinuation in both patients. However, AAU relapsed and the decision was taken to switch etanercept to another TNF blocker: infliximab for the first case (who had been treated by adalimumab before) and adalimumab for the second case, with no AAU relapse to date. AAU was more frequently reported with etanercept, the soluble receptor p55, than with monoclonal antibody TNF blockers. This discrepancy between TNF blockers may be due to the specific structure of etanercept, which is a fusion protein combining two extracellular ligand-binding portions of the human soluble TNF receptor p75 with the end Fc fragment of human immunoglobulin G1.

Since de novo uveitis is a rare event with approximately 1 case for 100 patient-years exposed to TNF blockers, ${ }^{14}$ occurrence in two cousins from the same family, both treated for AxSpA by etanercept, suggested a genetic predisposition to this paradoxical side effect with TNF blockers. Since the microsatellite, D9S157, on chromosome 9p was identified by genomewide scan to be associated with AAU in AxSpA, ${ }^{6}$ we analysed this region using several microsatellites in these two patients. Both patients shared an identical allele at three contiguous polymorphic markers, located at 9p21.3-p22.2: D9S157, D9S1684 and D9S162, but are different for D9S156 and D9S171. This locus covers approximately a $6 \mathrm{Mb}$ interval and contains some 37 genes. This identity might be an additional indication for a genetic predisposition to uveitis at this locus, and along these lines, it is noteworthy that the cluster of interferon type 1 genes is present in this region between markers D9S162 and D9S171.
Conversely, in our family, there is a probability of $1 / 16$ that this haplotype identity occurred by chance. Further experiments are required to determine the specific gene from this area related to AAU.

According to our experience and the findings of this genetic analysis, we would suggest avoiding etanercept among TNF blockers when patients present a familial history of uveitis.

Martin Killian, ${ }^{1}$ Renaud Touraine, ${ }^{2}$ Adamah Amouzougan, ${ }^{1}$ Thierry Thomas, ${ }^{1,3}$ Hubert Marotte ${ }^{1,3}$

${ }^{1}$ Rheumatology Department, University Hospital of Saint-Etienne, Saint-Etienne, France

${ }^{2}$ Laboratory of Genetics Saint-Etienne, University Hospital of

Saint-Etienne, Saint-Etienne, France

${ }^{3}$ INSERM U1059/LBTO, Université de Lyon - Université Jean Monnet, Saint-Etienne, France

Correspondence to Professor Hubert Marotte, Department of Rheumatology, Hôpital Nord, University Hospital of Saint-Etienne, 42055 Saint-Etienne, Cedex 02, France; hubert.marotte@chu-st-etienne.fr

Contributors MK, AA, TT and HM participated in the follow-up of patients. RT performed genetic analysis. All authors have reviewed the paper in questions, help draft the letter and gave consent for the final version.

Competing interests None.

Patient consent Obtained.

Provenance and peer review Not commissioned; internally peer reviewed.

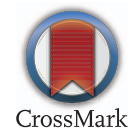

To cite Killian M, Touraine R, Amouzougan A, et al. Ann Rheum Dis 2015;74:e22.

Received 12 October 2014

Revised 29 October 2014

Accepted 7 November 2014

Published Online First 2 December 2014

Ann Rheum Dis 2015;74:e22. doi:10.1136/annrheumdis-2014-206776

\section{REFERENCES}

1 Sieper J, Koenig A, Baumgartner $S$, et al. Analysis of uveitis rates across all etanercept ankylosing spondylitis clinical trials. Ann Rheum Dis 2010;69:226-9.

2 Guignard S, Gossec L, Salliot C, et al. Efficacy of tumour necrosis factor blockers in reducing uveitis flares in patients with spondylarthropathy: a retrospective study. Ann Rheum Dis 2006:65:1631-4.

3 Fouache D, Goëb V, Massy-Guillemant N, et al. Paradoxical adverse events of anti-tumour necrosis factor therapy for spondyloarthropathies: a retrospective study. Rheumatology (Oxford) 2009;48:761-4.

4 Wendling D, Paccou J, Berthelot J-M, et al. New onset of uveitis during anti-tumor necrosis factor treatment for rheumatic diseases. Semin Arthritis Rheum 2011;41:503-10.

5 Marotte H, Cimaz R. Etanercept-TNF receptor and IgG1 Fc fusion protein: is it different from other TNF blockers? Expert Opin Biol Ther 2014;14:569-72.

6 Martin TM, Zhang G, Luo J, et al. A locus on chromosome 9p predisposes to a specific disease manifestation, acute anterior uveitis, in ankylosing spondylitis, a genetically complex, multisystem, inflammatory disease. Arthritis Rheum 2005;52:269-74. 